\title{
INFLUENCE OF PURIFICATION PROCESS ON THE CHARACTERISTICS OF ROMANIAN CALCIUM BENTONITE
}

\author{
ANA-MARIA GEORGESCU ${ }^{*}$, FRANÇOISE NARDOU ${ }^{2}$, DENISA NISTOR \\ ILEANA ${ }^{1}$ \\ I "Vasile Alecsandri" University of Bacau, Faculty of Engineering, Chemical and Food \\ Engineering Department, 157 Calea Marasesti street, 600115, Bacău, Romania \\ ${ }^{2}$ University of Limoges / CEC, SPCTS, UMR 7315 CNRS, 12 Rue Atlantis, 87068, Limoges \\ Cedex, France
}

\begin{abstract}
A calcium bentonite from Orasu Nou deposit (Romania) was used as raw material. The natural bentonite provided by S.C. Bentonita S.A., Satu Mare has the following mineralogical composition: $57 \%$ montmorillonite, $40 \%$ cristobalite, and $3 \%$ quartz. Due to the relatively high percentage of impurities in natural calcium bentonite, we decided to purify the raw material, in order to improve the quality of montmorillonite. Through purification procedure, well defined granulometric fractions with particles of less than $2 \mu \mathrm{m}$, are obtained. The crude and purified calcium bentonites were characterized by textural analysis, scanning electron microscopy (SEM) coupled with energy-dispersive Xray spectroscopy (EDX). The physical, structural and morphological characteristics are affected by the purification process. The purified bentonite can be used to obtain advanced materials, which can be tested as adsorbents for environmental remediation.
\end{abstract}

Keywords: montmorillonite, purification, surface area, pore volume, pore diameter, adsorption-desorption isotherm, microscopy

\section{INTRODUCTION}

The scientists believe that clays and clay minerals, either in its natural state or after modification, will be recognized as the materials of the 21 st century due to their abundance, low cost and environment friendly. Clays can be defined by their size distribution as being particles whose size is less than 2 micrometers, and they are hydrated lamellar or semi-lamellar silicates, in terms of mineralogical [1].

Mineralogists and chemists specialized in crystallography have defined the modern concept of clay minerals as aluminum silicates with water constitution and with layer structure. Clay minerals are constructed of two coordinative groups: tetrahedral (T) with central $\mathrm{Si}^{4+}$ cations and octahedral $(\mathrm{O})$ with central $\mathrm{Al}^{3+}, \mathrm{Fe}^{3+}$ or $\mathrm{Mg}^{2+}$ cations [2]. Binding of coordinative groups from network leads to structural elements, which in the case of clay minerals, are presenting in the form of sheets and / or chains that gives them a characteristic layered and filamentous structure [1].

The 2:1 layer structure of phyllosilicates consists of an octahedral sheet which is sandwiched between two opposing tetrahedral sheets (Figure 1) [3]. The connection between layers is very weak, the external surfaces of lack of active oxygen layers being bound by residual van der Waals forces [1].

\footnotetext{
${ }^{*}$ Corresponding author, email: ana.georgescu@ub.ro

(C) 2016 Alma Mater Publishing House
} 


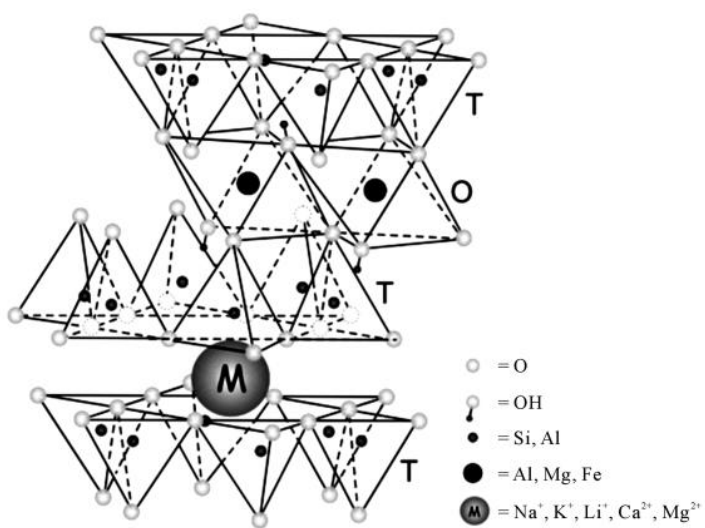

Fig. 1. Representation of 2: 1 layer structure of phyllosilicate (montmorillonite):

$\mathrm{T}$ - tetrahedral layer; $\mathrm{O}$ - octahedral layer [3].

Montmorillonite is a dioctahedral three-layer clay (2:1 clays, TOT): an $\mathrm{AlO}(\mathrm{OH})$ octahedral sheet is between two tetrahedral $\mathrm{SiO}_{4}$ layers. The distance between the layers is not fixed (-O-O-bonds), so the layers can be expanded. Due to the layered structure, montmorillonite has two surface types: external and internal surfaces. The external surface is the surface of the particles (edge surface), and its size depends on particle size distribution. The internal surface is the surface between the layers (interlayer surface), and its size can be determined by introducing substances into the interlayer space (e.g., water). The internal surface area is independent of particle size distribution [4]. The crystal lattice of montmorillonite may have isomorphic substitutions both in the tetrahedral and octahedral positions. In the tetrahedral positions, the central tetravalent silicon can be substituted by trivalent aluminum ions; in the octahedral positions, the trivalent aluminum ions can be substituted by bivalent (usually magnesium and iron (II)) cations of similar sizes [1, 4]. As a result, the layer charge is negative and is mostly neutralized by the hydrated cations in the interlayer space [4].

Cation exchange is the determining interfacial process of the internal surfaces of montmorillonite. In montmorillonite, similar to other minerals, when the size of the exchanged cation is similar to the pore sizes in the crystal lattice, cations can build into the crystal lattice and, consequently, they reduce the negative layer charge. Other neutral molecules or cationic substances can also be sorbed in the interlayer space and on the external surfaces as well. They play an important role in defining the internal and total surface area and catalytic properties, and they may have an effect on the hydrophobicity of the mineral, as well as playing an important role in the production of pillared materials, etc.

Clay minerals have special adsorption properties, present plasticity, compressive strength and good permeability. In Romania, natural clays are used principally as raw materials for building materials, refractories, ceramics and molds for casting in metallurgy. Worldwide, the use of clays is found in many areas, the natural materials being chemical, mechanical, thermal or combined methods changed. Such materials may be successfully used in areas such as environmental remediation (adsorbents or ion exchange), food, medicine and pharmacy, manufacture of pigments for paints, paper, insecticides etc. All these applications demonstrate that indigenous natural bentonites with a high content of montmorillonite, is insufficiently exploited natural wealth.

The aim of this paper is to obtain a clay mineral containing a higher quantity of montmorillonite. The raw material used is a Romanian calcium bentonite, whose composition consists into a high quantity of montmorillonite (but not enough), cristobalite and quartz. It is intended that Romanian calcium bentonite to be used as potential adsorbent for environmental remediation. The impurities presented in the composition of natural bentonite can negatively influence the adsorption characteristics of the future synthetized nanomaterials.

\section{EXPERIMENTS}

\subsection{Materials}

The purification process consists in dispersion of natural calcium bentonite (CaBent-nat) in distilled water in order to obtain a diluted suspension $(0.4 \mathrm{wt} \%)$ [5]. The suspension is stirred for $3 \mathrm{~h}$ at room temperature, till complete homogenization. Bentonite suspensions are introduced into graduated cylinders of 2 L for sedimentation, at room temperature (Figure 2). 


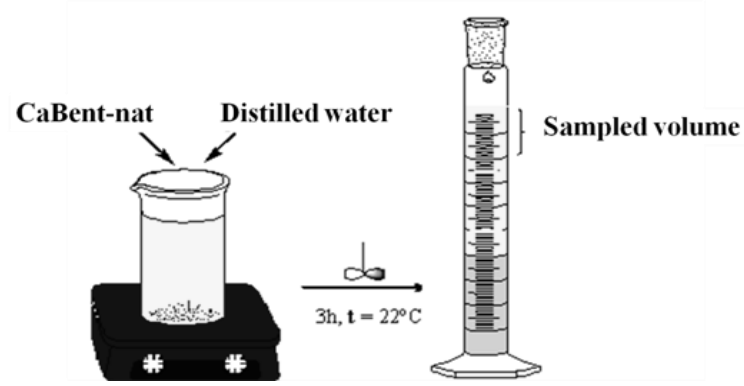

Fig. 2. Schematic representation of bentonite purification principle.

Based on Stokes' law, the time needed to recover fractions that contain the particles less than $2 \mu \mathrm{m}$ is determined. Bentonite fractions are centrifuged, the supernatant is removed, and the recovered clay is dried at $105{ }^{\circ} \mathrm{C}$, for $15 \mathrm{~h}$. The purified calcium bentonite (CaBent-pur) is ground and sieved through a $63 \mu \mathrm{m}$ sieve, in order to recover only the fine particles.

\subsection{Characterization methods}

The adsorption-desorption isotherms and the pore size distribution were measured with a Micromeritics ASAP 2010 device. The samples were degassed at $473 \mathrm{~K}$, for $16 \mathrm{~h}$. The value $0.1620 \mathrm{~nm}^{2}$ was taken for all samples as the $\mathrm{N}_{2}$ molecular cross-sectional area. Pore size distribution for materials was calculated according to BarretJoyner-Halenda (BJH) method from the nitrogen desorption isotherms.

The morphological analyses of the materials were realized through scanning electron microscopy (SEM), using a Philips XL30 device and through transmission electron microscopy (TEM), using a TEM JEOL 2012 apparatus. The samples were sputter-coated with $\mathrm{Au}$ and Pd under vacuum in argon atmosphere, using Baltec SCD 050 apparatus, in order to achieve sufficient electrical conductivity. Particle images were obtained with a secondary electron detector. Semi-quantitative chemical analyses of the samples were determined using an EDX device which is coupled with the SEM apparatus.

\section{RESULTS AND DISCUSSION}

The shape of nitrogen adsorption-desorption isotherm obtained for the purified calcium bentonite is of type IV [6] (Figure 3), being similar with the raw material one, which was presented in a previous paper [7].

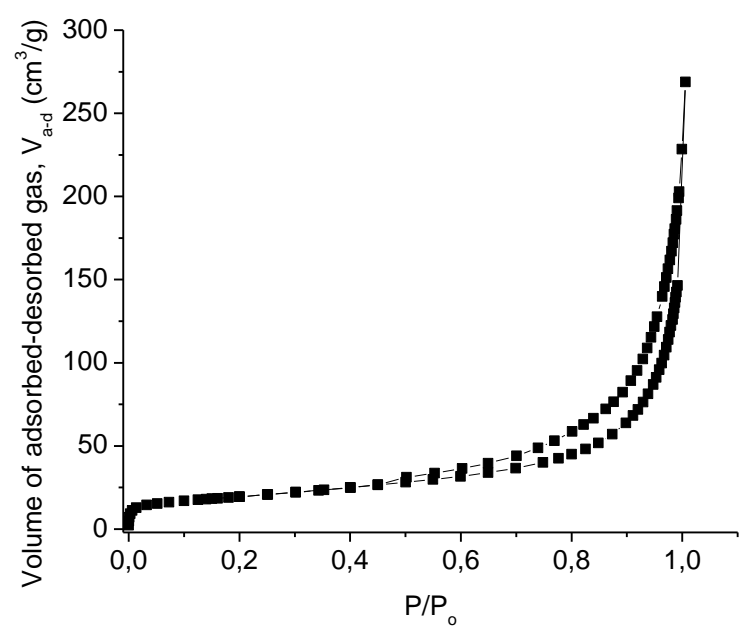

Fig. 3. Nitrogen adsorption-desorption isotherm of CaBent-pur.

This isotherm is specific to mesoporous adsorbents. According to IUPAC classification [8], the resulted hysteresis is of type $\mathrm{H} 3$, due to the difference between the adsorption and desorption isotherms. This type corresponds to the formation of aggregates of slit-like pores, with variable sizes. 
The nitrogen isotherm have a vertical adsorption branch at a relative pressure close to unity and a desorption branch close to medium pressure. Representation of isotherm also indicates that the purified montmorillonite contains appreciable amount of mesopores, but micropores in smaller amounts too. The adsorption capacity of the material is up to $275 \mathrm{~cm}^{3} / \mathrm{g}$, being higher than that of CaBent-nat [7].

The porosity parameters of studied materials are shown in Table 1.

Table 1. Textural properties derived from the nitrogen adsorption at $77 \mathrm{~K}$

\begin{tabular}{|c|c|c|c|c|c|c|}
\hline Material & \multicolumn{6}{|c|}{ Area } \\
\hline & $\begin{array}{l}\text { Langmuir } \\
\text { surface } \\
\text { area }\left(\mathrm{m}^{2} / \mathrm{g}\right)\end{array}$ & \multicolumn{2}{|c|}{$\begin{array}{l}\text { Micropore } \\
\text { area }\left(\mathrm{m}^{2} / \mathrm{g}\right)\end{array}$} & $\begin{array}{c}\text { External } \\
\text { surface area } \\
\left(\mathbf{m}^{2} / \mathbf{g}\right)\end{array}$ & $\begin{array}{c}\text { BJH adsorption } \\
\text { cumulative surface area of } \\
\text { pores }\left(\mathrm{m}^{2} / \mathrm{g}\right)\end{array}$ & $\begin{array}{c}\text { BJH desorption } \\
\text { cumulative surface area of } \\
\text { pores }\left(\mathrm{m}^{2} / \mathrm{g}\right) \\
\end{array}$ \\
\hline CaBent-nat & 62 [7] & \multicolumn{2}{|c|}{1 [7] } & 44 [7] & 52.83 & 65.93 \\
\hline CaBent-pur & 92.80 & \multicolumn{2}{|c|}{9.8} & 58.2 & 57 & 79.2 \\
\hline & \multicolumn{6}{|c|}{ Volume } \\
\hline Material & \multicolumn{2}{|c|}{$\begin{array}{l}\text { Total pore volume } \\
\left(\mathrm{cm}^{3} / \mathrm{g}\right)\end{array}$} & \multicolumn{2}{|c|}{$\begin{array}{l}\text { Micropore volume } \\
\left(\mathrm{cm}^{3} / \mathrm{g}\right)\end{array}$} & $\begin{array}{c}\text { BJH adsorption } \\
\text { cumulative pore volume of } \\
\text { pores }\left(\mathrm{cm}^{3} / \mathrm{g}\right)\end{array}$ & $\begin{array}{c}\text { BJH desorption } \\
\text { cumulative pore volume of } \\
\text { pores }\left(\mathrm{cm}^{3} / \mathrm{g}\right)\end{array}$ \\
\hline CaBent-nat & \multicolumn{2}{|c|}{0.231} & & 0.0029 & 0.2668 & 0.4576 \\
\hline \multirow[t]{2}{*}{ CaBent-pur } & \multicolumn{2}{|c|}{0.200} & & 0.0048 & 0.2105 & 0.3082 \\
\hline & \multicolumn{6}{|c|}{ Pore size } \\
\hline Material & \multicolumn{4}{|c|}{ Adsorption average pore diameter $(\AA)$} & $\begin{array}{c}\text { BJH adsorption average } \\
\text { pore diameter }(\AA)\end{array}$ & $\begin{array}{l}\text { BJH desorption average } \\
\text { pore diameter }(\AA)\end{array}$ \\
\hline CaBent-nat & \multicolumn{4}{|c|}{164.41} & 190.88 & 265.56 \\
\hline CaBent-pur & \multicolumn{4}{|c|}{117.75} & 147.66 & 155.70 \\
\hline
\end{tabular}

As expected, the purification process caused an increase of Langmuir surface area and both of micropore area, micropore volume and external surface area with respect to the parent clay. The Langmuir surface area was calculated from adsorption data in the relative pressure range of $0.01-0.05$, using a nitrogen molecule crosssectional area of $0.162 \mathrm{~nm}^{2}$. The total pore volume was assessed from the amount of nitrogen adsorbed at a relative pressure of 0.99 . In the case of pore size characteristics, the average pore diameter properties of CaBentpur decrease in comparison with raw material.

The pores size distributions of studied materials were determined from desorption isotherm branches and are presented in Figure 4.

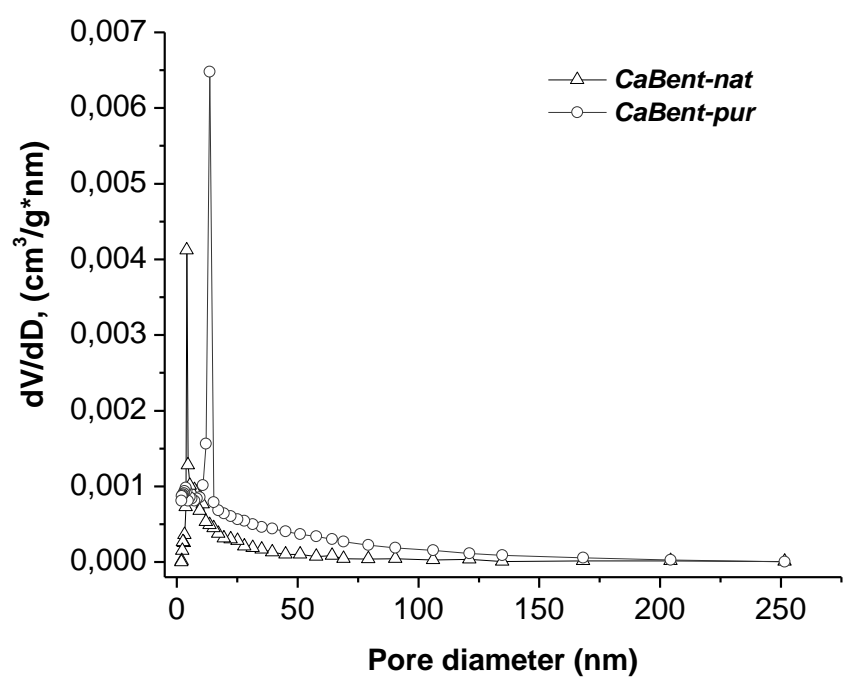

Fig. 4. Pores size distribution curve of CaBent-nat and CaBent-pur.

The natural bentonite contains meso- and macropores, due to the presence in its structure of minerals with different characteristics. The pore size distribution curve of the studied materials is modal. CaBent-nat presents a peak at about $4.1 \mathrm{~nm}$ and CaBent-pur at about $13.5 \mathrm{~nm}$. As clearly shown in Figure 4, an important increase of 
the adsorbed volume by CaBent-pur takes place as a result of the purification processes. The textural analyses of materials show that the purification process led to the improvement of porosity, which is one of the most important properties of adsorbents.

The semi-quantitative chemical analysis of materials is shown in Figure 5.
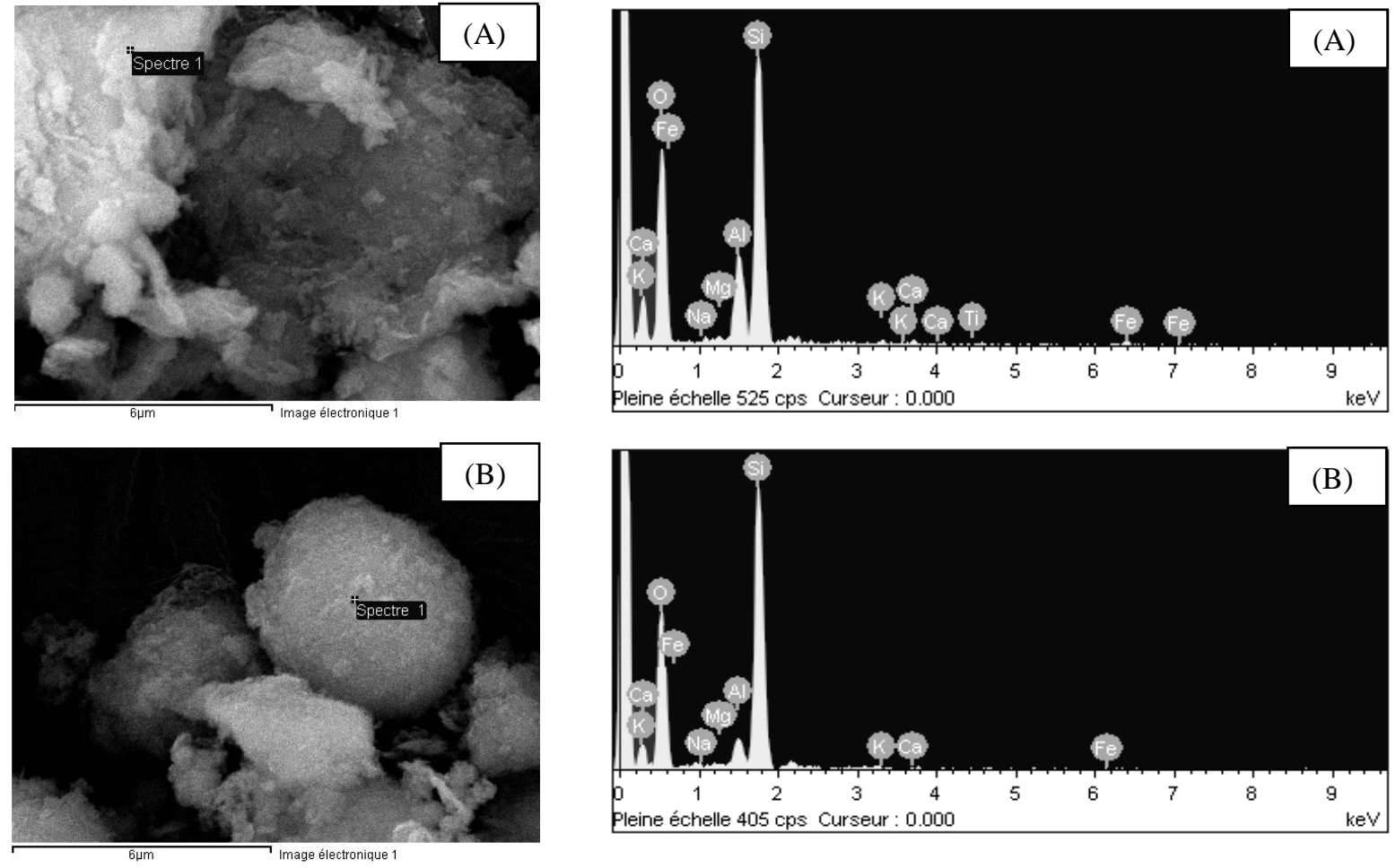

Fig. 5. SEM images and EDX spectres of CaBent-nat (A) and CaBent-pur (B).

The most abundant components of bentonites are $\mathrm{Si}^{2+}$ and $\mathrm{Al}^{3+}$, which represent the main components of clay minerals. In the composition of bentonites $\mathrm{Na}^{+}, \mathrm{Ca}^{2+}, \mathrm{K}^{+}$and $\mathrm{Mg}^{2+}$ ions can be observed, these being the interlayer cations between the clay sheets. The absence of titanium ions and the diminution of iron ions from the composition of CaBent-pur confirm that the purification process has been achieved. The studied materials have the tendency to stay together in small aggregates of nanoparticles, having distinct porosity, as are presented in SEM microimages.

\section{CONCLUSIONS}

The physical, structural and morphological characteristics of Romanian calcium bentonite are affected by the purification process. Although the purification process of bentonite is an extra step for the obtaining of chemically modified clays, the improved characteristics of purified clay confirm the necessity of this operation.

Romanian calcium bentonite, due to its high montmorillonite content, to its high natural availability and low cost, is a good candidate for the development of materials used in environmental remediation.

\section{Acknowledgements}

This paper was realized with the support of BRAIN project: "Doctoral scholarships as an investment in intelligence", financed by the European Social Found and Romanian Government. These results were achieved thanks to the support of SPCTS Laboratory from University of Limoges (C. Penot, T. Chartier, M. Soustre, P. Carles). 


\section{REFERENCES}

[1] Caillère, S., Hénin, S., Rautureau, M., Minéralogie des argiles. Structure et proprietes physico-chimiques, vol. 1, INRA et Masson, Paris, 1982.

[2] Murray, H.H., Applied clay mineralogy occurrences, Processing and Application of Kaolins, Bentonites, Palygorskite-Sepiolite, and Common Clays, Elsevier, vol. 2, 2007.

[3] R. Pusch, Knutsson S., Al-Taie L., Mohammed M. H., Optimal ways of disposal of highly radioactive waste Natural Science, vol. 4, 2012, p. 906-918.

[4] Nagy, N.M., Kónya, J., Interfacial chemistry of rocks and soils (Surfactant science series, 148), CRC Press Taylor \& Francis Group, New York, 2010.

[5] Khalaf, H., Bouras, O., Perrichon, V., Synthesis and characterization of Al-pillared and cationic surfactant modified Al-pillared Algerian bentonite, Microporous Materials, vol. 8, no. 3-4, 1997, p. 141-150.

[6] AlOthman, Z.A., A review fundamental aspects of silicate mesoporous materials, Materials, vol. 5, 2012, p. 2874-2902.

[7] Georgescu, A.M., Brabie, G., Nistor, I.D., Penot, C., Nardou, F., Synthesis and characterization of Crpillared clays: modelling using factorial design methodology, Journal of Porous Materials, vol. 22, no. 4, 2015, p.1009-1019.

[8] Rouquerol, F., Rouquerol, J., Sing, K., Adsorption by powders and porous solids, Academic Press, San Diego, 1999. 